\title{
The recovery of valuable metals and recycling of alumina from a waste spent hydroprocessing catalyst: extraction with Na salts
}

\author{
M. Marafi, M. S. Rana \& H. Al-Sheeha \\ Kuwait Institute for Scientific Research, Kuwait
}

\begin{abstract}
Considering the refinery importance, a spent catalyst recovery study was carried out on industrial spent residue hydroprocessing catalysts that contained high levels of metals. The spent catalyst was de-oiled, de-coked, crushed and ground to a fine powder, which was then subject to further treatment for metal recovery. In the extraction process, metals were recovered through hydrometallurgical routes using $\mathrm{NaOH}$, and $\mathrm{Na}_{2} \mathrm{CO}_{3}$ as roasting mediator as well as an extracting agent. The effectiveness of the aqueous basic solution extraction of Mo, $\mathrm{V}, \mathrm{Ni}$ and $\mathrm{Al}$ from the refinery spent catalyst is reported as a function of roasting agent, temperature, concentration, leaching time and temperature. The optimum leaching conditions were achieved in order to obtain a maximum recovery of $\mathrm{Mo}$, Ni and $\mathrm{V}$ metals, corresponding to a time of $1 \mathrm{~h}$, a temperature of $700^{\circ} \mathrm{C}$ and a concentration of $30 \mathrm{wt} \%$ with soda roasting, while the caustic digestion process's maximum recovery for all metals was at $250^{\circ} \mathrm{C}$ in temperature. The metals were recovered as corresponding salt, while alumina was recovered as boehmite, which was further dried and calcined in order to get the corresponding oxides in pure form. The aim of this study is to recover or recycle a waste catalyst as valuable metals and support (alumina) from the spent catalyst.

Keywords: spent catalyst, recycling, hazardous waste, residue hydroprocessing, waste utilization.
\end{abstract}

\section{Introduction}

In recent years, worldwide growing demand for metals can be associated with the current investigation as a secondary source of metals. In the petroleum refinery, huge tonnage of spent catalyst wastes are being generated, which have 
high content of metals and valuable alumina support. Therefore, refineries look forward to recycling options, where recovered metals or alumina can either be reused for catalyst preparation or can be used in the metal industries. Moreover, the recycling methodologies are eco-friendly and cost-effective. Refineries processes such as fluid catalytic cracking (FCC), reforming, isomerisation, spent hydroprocessing (hydrotreating and hydrocracking) are the key catalytic processes which generate spent catalysts. Hydroprocessing is one of the most important processes that produce a large amount of spent catalyst. Spent hydroprocessing catalysts are rich in metal values like $\mathrm{Mo}, \mathrm{Co}, \mathrm{Ni}, \mathrm{V}, \mathrm{Fe}$ and $\mathrm{Al}$, which are usually in the form of metal oxides and sulfides [1]. Usually, catalysts are deactivated during the catalytic processing of dirty feedstock; as a result catalysts decrease their activity mainly due to fouling, poisoning and/or thermal degradation/sintering [2-5]. The deactivation of the spent hydroprocessing catalyst has been reported as fouled with coke and metal $(\mathrm{V}+\mathrm{Ni})$ deposition [6, 7]. In Kuwait, catalytic hydrotreating processes are used extensively in Kuwait National Petroleum Company's (KNPC) three refineries, which generate large quantities (6000-7000 t) of spent catalysts as solid wastes every year. The amount of spent catalyst waste is expected to increase further in the coming years because of a forth new refinery and increasing diesel hydrotreating capacity to meet the growing demand for clean fuel with ultralow sulfur diesel. Generally, these spent catalysts are abandoned in the land for their disposal. Landfill of the spent catalyst is neither an eco-friendly process nor economically favorable mainly due to harmful effects (metal leaching in earth) on life and requirement of huge land. Thus, safe handling and disposal of spent catalysts in an environmentally acceptable way is a huge concern for a small country like Kuwait. Hence, it is worthy to recover the metal as well as support for which extensive research works have been carried out using pyro-metallurgical and hydrometallurgical techniques that have been applied and investigated in order to recover valuable metal and support from the spent hydroprocessing catalyst.

Thus, the recycling and utilization of spent catalysts were, therefore, considered important from an economic as well as an environmental point of view. The rejuvenation and reactivation of spent residue hydroprocessing catalysts were investigated and studied by several authors [8-16]. Use of spent catalyst for the preparation of an active hydrodemetallization catalyst by reprocessing spent catalyst was also studied [17]. The recycling and utilization of spent catalyst, two new processes, one for the reclamation of valuable metals ( Mo, Ni, Co and V) and the other for the recovery of special grades of alumina, such as boehmite and $\gamma$-alumina with high surface area and controlled pore size from spent hydroprocessing catalysts, were investigated and patented [15].

Fresh hydrotreating catalysts usually consist of Mo and Ni or Co supported on $\gamma-\mathrm{Al}_{2} \mathrm{O}_{3}$. Utilization of the alumina and metals recovered from spent catalysts in the preparation of active new hydrotreating catalysts will increase their economic value significantly, and will lead to complete recycling of the spent catalyst in a profitable way since a low value waste is transformed to a high value product. Also no work has been reported particularly on the high purity alumina is 
obtained, which can, be either used as hydrotreating (HDT) support or can be sold as a product in a commercial market. Hence, investigation in this direction is, therefore, important as it will help in finding cost-effective routes for solving the environmental problem of spent catalyst wastes [18].

The investigations are carried out as a function of leaching time, temperature and concentration $\left(\mathrm{Na}_{2} \mathrm{CO}_{3}\right.$ and $\left.\mathrm{NaOH}\right)$, and their effect on metals and alumina recovery processing. Various parameters have been tested with the objective to optimize or enhance the efficiency of metals as well as support recoveries from the spent hydroprocessing catalyst. A considerable attention has been focused on obtaining high grade alumina.

\section{Experiment}

A spent catalyst containing valuable metals like $\mathrm{Ni}, \mathrm{Co}, \mathrm{V}$, Mo and $\mathrm{Al}$, was obtained from atmospheric residue desulfurization (ARDS) unit of KNPC Company. The deposited species and spent catalyst was analyzed by X-ray diffraction and SEM-EDS (results are not shown), indicated that considerable amount of foreign species have been reported, as shown in Table 1.

The catalysts were in the form of cylindrical extrudates of an approximate diameter of $0.4 \mathrm{~mm}$ and length 5 to $6 \mathrm{~mm}$, which were de-oiled, de-coked, crushed and ground to a fine powder (particle size $<500 \mu \mathrm{m}$ ) using standard procedures as described in previous literature $[9,16]$. The de-coked spent hydroprocessing catalyst was roasted with $\mathrm{NaOH}$ and $\mathrm{Na}_{2} \mathrm{CO}_{3}$, and subsequently, Mo and V metal solution were separated or leached as a function of leaching $\mathrm{pH}$, time, temperature and concentration. The roasting conditions were optimized in order to obtain complete roasting and leaching of Mo and V as sodium salts in aqueous solution. The roasted mixture was further dissolved in hot water and refluxed for $1 \mathrm{~h}$ that dissolved $\mathrm{V}$ and Mo species, while nickel, cobalt and aluminum remained undissolved as residue (solid) after water treatment. The solution was filtered and washed, from which dissolved species (mainly $\mathrm{V}$ and Mo) were separated as liquid solution, while the undissolved remained as solid.

Table 1: Composition of catalyst before and after decoking.

\begin{tabular}{|c|l|l|l|}
\hline \multirow{2}{*}{ Catalyst properties } & \multicolumn{4}{l|}{ Composition of catalyst, wt\% } \\
\cline { 2 - 4 } & Fresh & Spent & De-coked \\
\hline Specific surface area (SSA), $\mathrm{m}^{2} / \mathrm{g}$ & 252 & 102 & 235 \\
\hline Total pore volume (TPV), $\mathrm{ml} / \mathrm{g}$ & 0.58 & 0.05 & 0.51 \\
\hline Average pore diameter (APD), nm & 16.2 & 8.7 & 13.0 \\
\hline Catalyst composition & & & \\
\hline $\mathrm{Mo}$ & 8.0 & 7.46 & 6.73 \\
\hline $\mathrm{Ni}$ & 3.3 & 4.8 & 4.3 \\
\hline $\mathrm{V}$ & - & 9.8 & 10.0 \\
\hline $\mathrm{Carbon}$ & - & 18.1 & $<1$ \\
\hline $\mathrm{Al}_{2} \mathrm{O}_{3}$ & - & 43.5 & - \\
\hline
\end{tabular}


The residue mixed with $\mathrm{NaOH}$ solution mixture was stirred in a high pressure autoclave at relatively high temperatures (ranging from 30 to $250^{\circ} \mathrm{C}$ ) and pressures (ranging from 2 to 15 bars) for $3 \mathrm{~h}$. Sodium aluminate, thus formed by alkali digestion, was separated from the un-reacted $\mathrm{NiO}$ or $\mathrm{CoO}$ as an insoluble residue by filtration. The filtrate, sodium aluminate solution, was then neutralized by $\mathrm{CO}_{2}$ bubbling for two hours and converted to $\mathrm{A} 1(\mathrm{OH})_{3}$. The $\mathrm{A} 1(\mathrm{OH})_{3}$ white precipitate was separated by filtration and the residue was washed with distilled water several times, and then filtered.

The aluminum trihydroxide $\mathrm{A} 1(\mathrm{OH})_{3}$ obtained from the spent catalyst was subject to hydrothermal treatment in a high pressure autoclave in order to modify its textural properties with variation in hydrothermal conditions such as at a different temperature in the range 60 to $240^{\circ} \mathrm{C}$ for $10 \mathrm{~h}$, and with a variation in digestion time 4 to $40 \mathrm{~h}$ at $200^{\circ} \mathrm{C}$. The hydrothermally treated product was filtered and washed, and then dried at $110^{\circ} \mathrm{C}$ for $12 \mathrm{~h}$. The dried boehmite was finally calcined at $500^{\circ} \mathrm{C}$ for $4 \mathrm{~h}$, which converted boehmite into $\gamma$-alumina. The $\gamma-\mathrm{Al}_{2} \mathrm{O}_{3}$ recovered from the spent catalyst had surface area and porosity values, and could be used in the preparation of catalyst supports as shown in Figure 1.

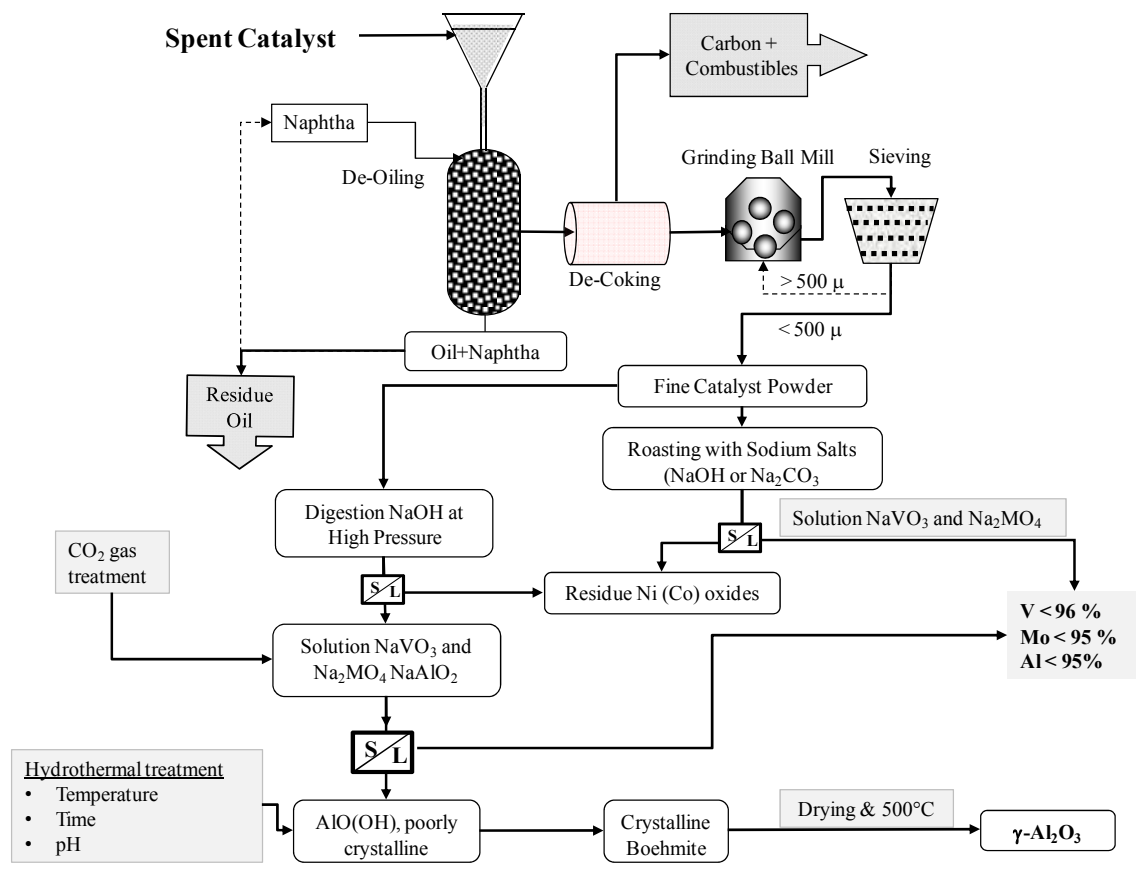

Figure 1: Soda roasting process for metal and high purity alumina recovery. 


\section{Results and discussion}

Soda ash roasting: Refinery spent hydroprocessing catalyst which was covered by a layer of heavy petroleum hydrocarbon (residue), was washed with naphtha. As in Figure 1, the naphtha was recycled (distillation) in the process while considerable amounts of residual oil were recovered and used for the de-coking heating section. During de-coking, the surface metal sulfides (Ni, Mo and V) were converted into metal oxides, a slight weight loss of the catalyst was attributed to metal sulphide oxidation into metal oxide as shown in eqn. 1 for Mo:

$$
2 \mathrm{MoS}_{2(\mathrm{~s})}+7 \mathrm{O}_{2(\mathrm{~g})} \rightarrow 2 \mathrm{MoO}_{3(\mathrm{~s})}+4 \mathrm{SO}_{2(\mathrm{~g})}
$$

The washed and decoked spent catalyst was then ground and converted into a fine power of $>500$ micro size and sieved. The effect of particle size on the extraction of metal is crucial in order to obtain a uniform sample for chemical analysis and leaching experiments. It has been reported that the highest extraction efficiency was achieved at a catalyst particle size of less than $75 \mu \mathrm{m}$ [19]. Therefore, the smaller the particle size the greater the possibility of surface contact between metals and leaching agents, which enhance the extraction capacity of metals.

\subsection{Roasting with $\mathrm{Na}_{2} \mathrm{CO}_{3}$}

The de-coked spent catalyst was mixed with $\mathrm{Na}_{2} \mathrm{CO}_{3}$, and the mix was roasted in the presence of air in a muffle furnace at high temperatures (e.g. $\left.700^{\circ} \mathrm{C}\right)$ to convert the Mo and $\mathrm{V}$ present in the spent catalyst to $\mathrm{Na}_{2} \mathrm{MoO}_{4}$ and $\mathrm{NaVO}_{3}$, respectively. The liquid/solid (L/S) was separated by filtration and was measured for soluble fraction by atomic absorption spectrometry. Ni and Al present in the catalyst did not react with $\mathrm{Na}_{2} \mathrm{CO}_{3}$ and its extraction is negligible. The roasted product was treated with water at $100^{\circ} \mathrm{C}$ by continuous stirring to dissolve the $\mathrm{Na}_{2} \mathrm{MoO}_{4}$ and $\mathrm{Na}_{2} \mathrm{VO}_{3}$ salts, which were separated as water soluble salts; the insoluble residue contained $\mathrm{NiO}$ and $\mathrm{Al}_{2} \mathrm{O}_{3}$. The total soluble fraction or metals leached are expressed as a percentage of the initial content and the mass of the catalyst used for leaching. The chemical reactions of both (roasting and hot water) treatments of the NiMo spent catalyst have been reported in previous studies [16]. On the other hand, the chemical reaction phenomenon was reported by Angelidis et al. [20], where deposited metals (Mo, $\mathrm{V}$ and $\mathrm{Ni}$ ) were involved sodium salt reactions, (eqns. 2-4), where salts are soluble in the aqueous medium:

$$
\begin{aligned}
\mathrm{MoO}_{3}+\mathrm{Na}_{2} \mathrm{CO}_{3} & \rightarrow \mathrm{Na}_{2} \mathrm{MoO}_{4}+\mathrm{CO}_{2} \\
\mathrm{~V}_{2} \mathrm{O}_{5}+\mathrm{Na}_{2} \mathrm{CO}_{3} & \rightarrow 2 \mathrm{NaVO}_{3}+\mathrm{CO}_{2} \\
\mathrm{NiO}+\mathrm{Na}_{2} \mathrm{CO}_{3} & \rightarrow 2 \mathrm{NiVO}_{3}+\mathrm{CO}_{2}
\end{aligned}
$$


The degree of metal leaching was calculated assuming that metal oxides are in oxide form in the roasted spent catalyst and taking into account the watersoluble fraction of metals such as Mo and $\mathrm{V}$. The chemical equations indicated that $\mathrm{Mo}\left(\mathrm{MoO}_{3}\right)$ and $\mathrm{V}\left(\mathrm{V}_{2} \mathrm{O}_{5}\right)$ utterly reacted during the roasting, which means they are usually fully soluble in alkaline media as $\mathrm{MoO}_{4}{ }^{2-}$ and $\mathrm{VO}_{3}{ }^{1-}$, in the form of $\mathrm{Na}_{2} \mathrm{MoO}_{4}$ and $\mathrm{NaVO}_{3}$ respectively. These results are in agreement with a previous work carried out by Mohapatra and Park [21] that investigated the effect of the roasting temperature $\left(200\right.$ to $\left.600^{\circ} \mathrm{C}\right)$ on a spent $\mathrm{CoMo} / \mathrm{Al}_{2} \mathrm{O}_{3}$ catalyst. A similar type of reaction has been also reported for $\mathrm{NAOH}$ roasting [20]. However, the minimum amount of sodium salt require for stoichiometric, roasting conditions such as leaching time and temperature.

Effect of Roasting Time: The effect of roasting duration at constant temperature $\left(700^{\circ} \mathrm{C}\right)$ and concentration $\left(30 \% \mathrm{Na}_{2} \mathrm{CO}_{3}, 1: 13\right.$ molar ratio of spent catalyst and salt) was varied in the range of $10 \mathrm{~min}$ to $2 \mathrm{~h}$ in order to optimize the time required for the maximum recovery of metals. The extraction percentages of the Mo and V extraction are reported as a function of leaching time, as shown in Figure 2. Only Mo and V seem to react considerably, and a very small fraction of support (i.e. Al) is detected in the extracted solution. The recoveries of metals (Mo and V) were high even after 10 min of roasting, which further increased about $99 \%$ within the $60 \mathrm{~min}$ of time-on-stream. A further increase in the roasting time led to a slight decrease in the extraction percentage of both metals indicating less interaction with deposited metals, while metal interaction may enhance at a high temperature.

Effect of extractant $\left(\mathrm{Na}_{2} \mathrm{CO}_{3}\right)$ concentration: The amount of $\mathrm{Na}_{2} \mathrm{CO}_{3}$ mixed with the spent catalyst in the soda ash roasting experiments was varied from 10 to $35 \%$ in order to determine the optimum quantity of $\mathrm{Na}_{2} \mathrm{CO}_{3}$ to be used for maximum recovery of Mo and $\mathrm{V}$, as shown in Figure 3. The percentage

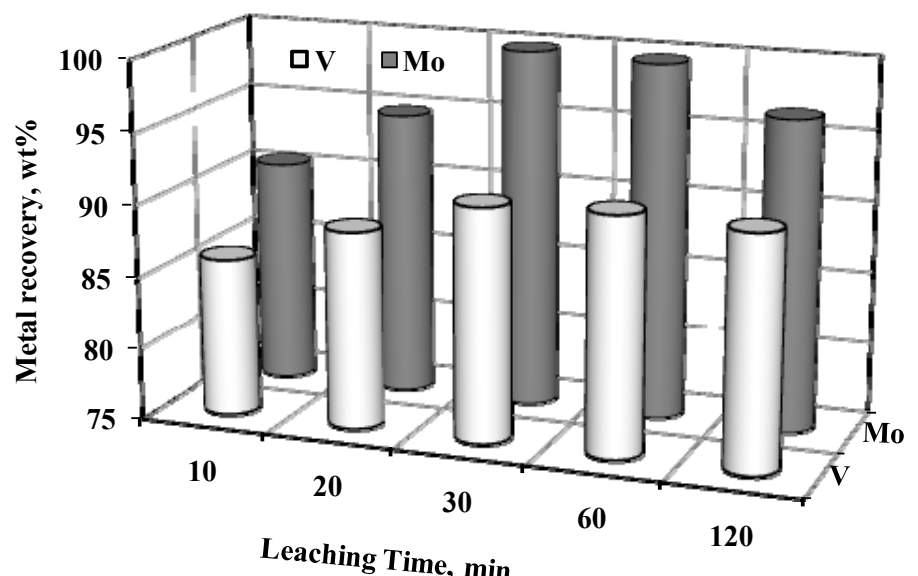

Figure 2: $\quad$ Effect of $\mathrm{Na}_{2} \mathrm{CO}_{3}$ leaching time on Mo and $\mathrm{V}$ metals recoveries at $700^{\circ} \mathrm{C}$ and with $30 \% \mathrm{Na}_{2} \mathrm{CO}_{3}$. 

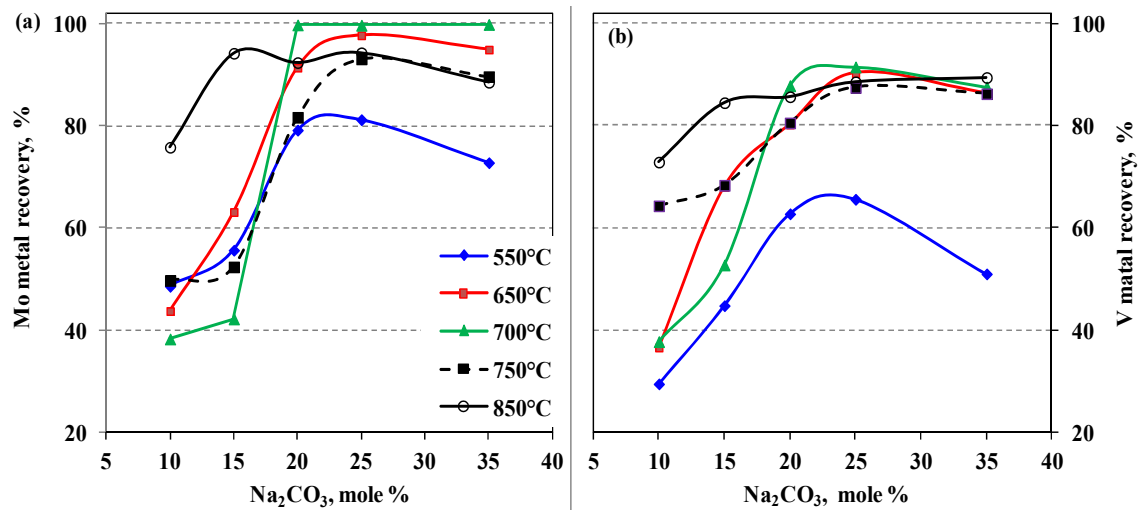

Figure 3: Effect of $\mathrm{Na}_{2} \mathrm{CO}_{3}$ concentration on the molybdenum (a) and vanadium (b) leaching.

extraction of $\mathrm{Ni}$ and $\mathrm{Al}$ was not significant when compared with $\mathrm{Mo}$ and $\mathrm{V}$ extractions. The recovery of both metals was very low, up to $15 \% \mathrm{Na}_{2} \mathrm{CO}_{3}$, in the mix. Increasing the amount of $\mathrm{Na}_{2} \mathrm{CO}_{3}$ to $20 \%$ led to a remarkable increase, where Mo recovery reached $99.7 \%$, while $\mathrm{V}$ remained at $85 \%$, in which recovery reached to $92 \%$ at $30 \% \mathrm{Na}_{2} \mathrm{CO}_{3}$. Therefore, in order to obtain more than $95 \%$ Mo and $\mathrm{V}$, the optimum amount of $\mathrm{Na}_{2} \mathrm{CO}_{3}$, i.e. $30 \mathrm{wt} \%$ should be added to the spent catalyst. It was observed that an optimum range of 20 to $30 \mathrm{wt} \% \mathrm{Na}_{2} \mathrm{CO}_{3}$ had a significant effect on Mo and $\mathrm{V}$ solubilization. However, a further increase in $\mathrm{Na}_{2} \mathrm{CO}_{3}$ metal recovery slightly decreased $\mathrm{V}$ in particular, which could be due to an intra-reaction with each other which probably occurs forming sodium percarbonate, and thereby decreases the availability of reactants to react with the catalyst, which limit the leaching efficiency [22].

Effect of Temperature: The temperature used for roasting the spent catalyst with $\mathrm{Na}_{2} \mathrm{CO}_{3}$ was varied in the range of 550 to $850^{\circ} \mathrm{C}$ to determine the optimum temperature required for the maximum conversion and extraction of $\mathrm{Mo}$ and $\mathrm{V}$ as sodium salts. The results obtained in these experiments are presented in Figure 4. It can be seen that $\mathrm{Na}_{2} \mathrm{CO}_{3}$ roasting was very effective for the selective recovery of both Mo and $\mathrm{V}$ from spent hydroprocessing catalysts.

These results clearly showed that the optimum temperature for the maximum recovery $\left(>99 \%\right.$ ) of $\mathrm{Mo}$ and $\mathrm{V}$ in the soda ash roasting process was $700^{\circ} \mathrm{C}$, while further increase in temperature let to lower recovery due to the increase in metal-metal interaction, which had a negative effect on the selective leaching of metals.

\subsection{Roasting with $\mathrm{NaOH}$}

Roasting of spent catalyst with caustic soda $(\mathrm{NaOH})$ followed by leaching with hot water was carried out to extract the metals present in the spent catalyst. Preliminary experiments revealed that Mo, V and Al present in the spent catalyst 


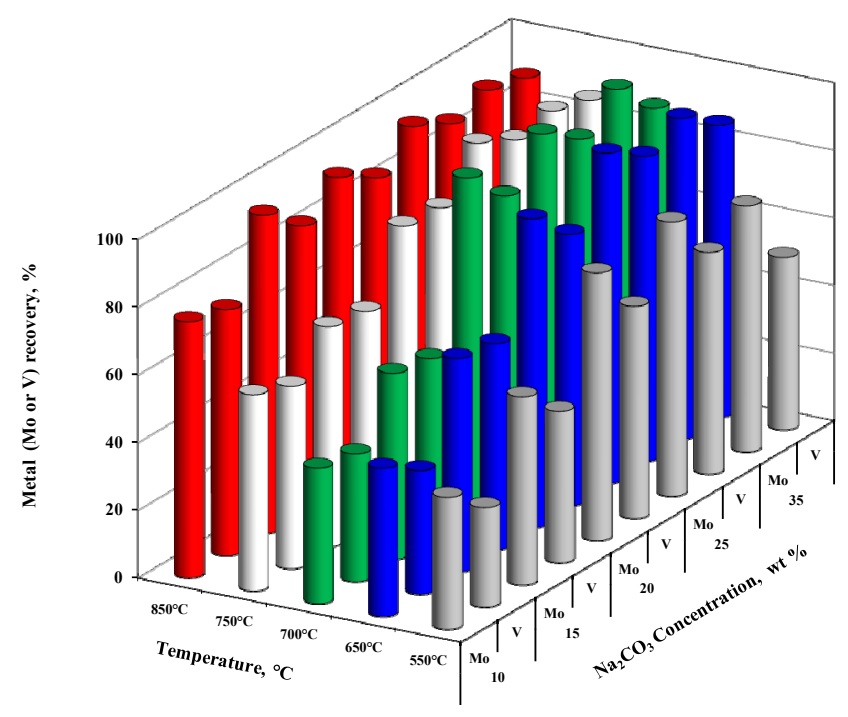

Figure 4: Effect of temperature and $\mathrm{Na}_{2} \mathrm{CO}_{3}$ concentration on metal.

reacted with $\mathrm{NaOH}$ during roasting at high temperatures to form $\mathrm{Na}_{2} \mathrm{MoO}_{4}$, $\mathrm{Na}_{2} \mathrm{VO}_{3}$ and $\mathrm{NaAlO}_{2}$. However, $\mathrm{Ni}$ did not react with $\mathrm{NaOH}$ under these conditions. The effects of roasting temperature and the amount of $\mathrm{NaOH}$ mixed with the spent have been studied in the subsequent section.

Effect of $\mathrm{NaOH}$ roasting temperature: The temperature used for the roasting of spent catalyst with $\mathrm{NaOH}$ was varied in the range of 300 to $550^{\circ} \mathrm{C}$ in order to determine the optimum temperature required for the extraction of $\mathrm{Mo}, \mathrm{V}$ and $\mathrm{Al}$ as sodium salts. The extraction of $\mathrm{Ni}$ using $\mathrm{NaOH}$ roasting is negligible while $\mathrm{Al}$ is considerably removed. From Figure 5 it is seen that Mo recovery is complete at around $100 \%$, even at $300^{\circ} \mathrm{C}$, and a further increase of up to $550^{\circ} \mathrm{C}$ had no significant impact. Similarly, V recovery was also high $97 \%$ at $300^{\circ} \mathrm{C}$, which reached $100 \%$ at $500^{\circ} \mathrm{C}$. Al recovery was however, low (around $75 \%$ ) at temperatures below $400^{\circ} \mathrm{C}$, which significantly increased at higher temperatures reaching the maximum (around 94\%) in the temperature range of 450 to $500^{\circ} \mathrm{C}$. It is clear from these results that more than $99 \%$ of Mo and $\mathrm{V}$, while around $94 \%$ of $\mathrm{Al}$ could be recovered from the spent catalyst by roasting with $\mathrm{NaOH}$ at temperatures in the range of 450 to $500^{\circ} \mathrm{C}$.

Effect of spent catalyst and $\mathrm{NaOH}$ ratio: A set of experiments were carried out as a function of extractant concentration $(\mathrm{NaOH})$, and a comparison was made for two different temperatures. The weight ratio between the spent catalyst and $\mathrm{NaOH}$ during roasting was varied in the range of 0.4 to 2.2 at fixed temperatures of $400^{\circ} \mathrm{C}$ and $450^{\circ} \mathrm{C}$, and at $60 \mathrm{~min}$ time-on-stream. The recovery of Mo and $\mathrm{V}$ strongly depended on roasting reagent concentration but $\mathrm{Ni}$ did not react with $\mathrm{NaOH}$, as shown in Figure 6. It is evident from the figure that Mo recovery increased from 87.7 to $99.9 \%$ when the ratio between the spent catalyst 
and $\mathrm{NaOH}$ in the mix was increased from 1:0.4 to 1:1.5. A further increase in the amount of $\mathrm{NaOH}$ amount in the mix to 1:2.2 led to a slight decrease on Mo recovery. Vanadium recovery also reached up to $98.3 \%$ at $1: 1.5$ ratio of $\mathrm{NaOH}$ and then decreased with further increase in the amount of $\mathrm{NaOH}$. It is evident from these results that the optimum mix ratio between the spent catalyst and $\mathrm{NaOH}$ for the maximum recovery of $\mathrm{Mo}, \mathrm{V}$ and $\mathrm{Al}$ with $\mathrm{NaOH}$ is in the range of 50 to $60 \mathrm{wt} \% \mathrm{NaOH}$ (about 1:1.5). An increase in the extraction efficiency was observed with an increase in the temperature, however, the tendency remained similar for both cases (Figure 6).

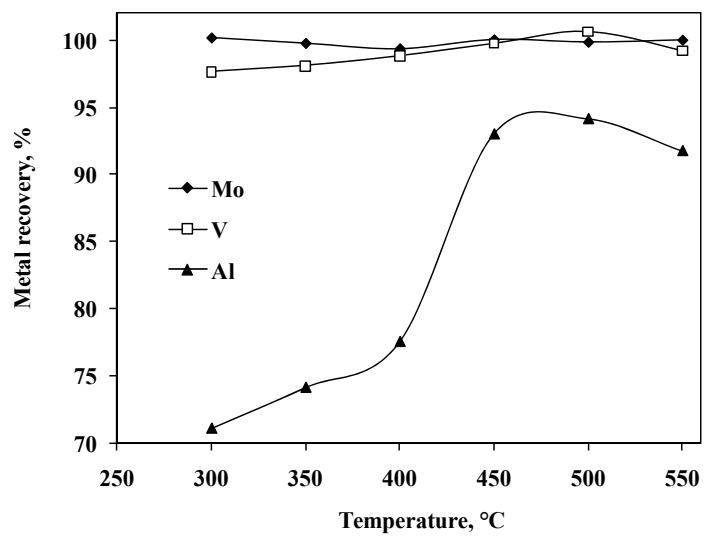

Figure 5: $\quad$ Effect of temperature on metal recovery with spent to $\mathrm{NaOH}$ molar ratio $1: 1.5$.

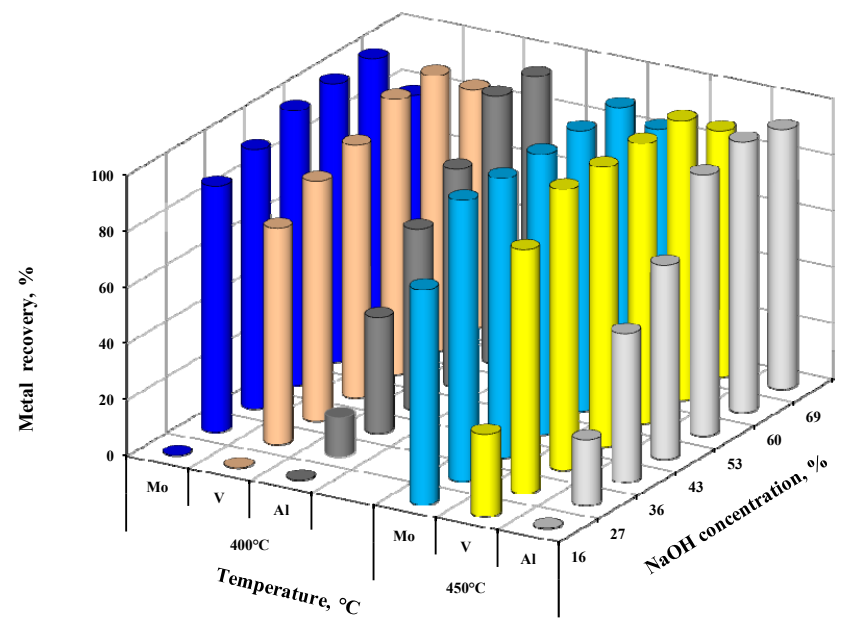

Figure 6: Effect of temperature and $\mathrm{NaOH}$ concentration on metal recovery. 


\subsection{Metal extraction by digestion with caustic soda at high pressure}

The de-coked spent catalyst was mixed with the $\mathrm{NaOH}$ solution and the mixture was stirred in a high pressure autoclave at relatively high temperatures (ranging from 150 to $250^{\circ} \mathrm{C}$ ) and pressures (ranging from 10 to 15 bars) for $3 \mathrm{~h}$. Sodium aluminate, thus formed by alkali digestion, was separated from the un-reacted $\mathrm{NiO}$ or $\mathrm{CoO}$ as an insoluble residue by filtration (Figure 1). The filtrate, sodium aluminate solution, was then neutralized by $\mathrm{CO}_{2}$ bubbling for two hours and converted to $\mathrm{A} 1 \mathrm{O}(\mathrm{OH})$. The $\mathrm{A} 1 \mathrm{O}(\mathrm{OH})$ white precipitate was separated by filtration, and the residual fraction was washed and filtered.

Effect of Temperature: The effect of temperature on the extraction of Mo and $\mathrm{V}$ was investigated. The solution was heated to different temperatures $\left(150\right.$ to $\left.250^{\circ} \mathrm{C}\right)$, as shown in Figure $7 \mathrm{a}$. It showed proportional behavior on metal leaching that increased with increasing temperature; however, $250^{\circ} \mathrm{C}$ appeared to be sufficient enough to recover about $98 \%, 95 \%$ and $93 \%$ of the $\mathrm{Mo}, \mathrm{V}$ and $\mathrm{Al}$, respectively. On the other hand, the effect of $\mathrm{NaOH}$ concentration on $\mathrm{Mo}$ and $\mathrm{V}$ extraction efficiency increased with an increase in the $\mathrm{NaOH}$ concentration, as shown in Figure $7 \mathrm{~b}$. For less than $4 \mathrm{wt} \%$ concentration, there was practically a $\mathrm{NaOH}$ deficiency effect, while there was no beneficial effect of increasing $\mathrm{NaOH}$ concentration more than $25 \%$. Figure $7 \mathrm{~b}$ reveals that caustic soda concentration of about 5\% seems to be sufficient enough to recover about $99 \%$ and $85 \%$ of the Mo and V present in the spent catalyst. Since the entire reaction for Mo was completed within $5 \mathrm{wt} \%$, a further increase in this time does not affect the molybdenum recovery while $95 \%$ vanadium recovery was obtained with $30 \%$ of $\mathrm{NaOH}$. An increase in caustic soda content improve Al leaching where at about $25 \mathrm{wt} \%$ caustic soda addition was considered to be the optimum. Al was extracted like $\mathrm{Al}(\mathrm{OH})_{3}$, which can be further converted into gamma alumina.

The Al metal separation process from the spent catalyst is the economic advantage which can be obtained by using sodium treatment methods $\left(\mathrm{Na}_{2} \mathrm{CO}_{3}\right.$ and $\mathrm{NaOH}$ ) that has more than $99 \%$ recovery and can be precipitated in the form
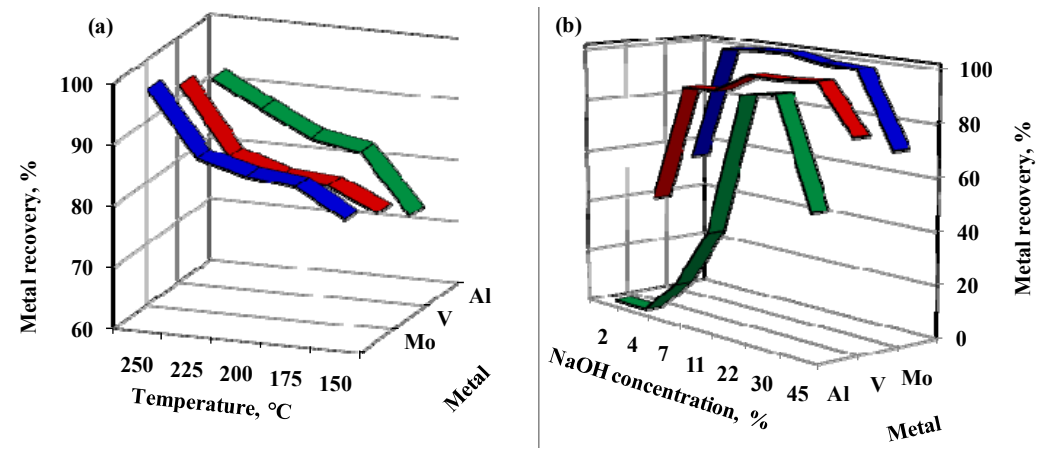

Figure 7: $\quad$ Effect of temperature (a) and $\mathrm{NaOH}$ concentration (b) on metal recovery of spent hydroprocessing catalysts. 
of bayerite $\mathrm{Al}(\mathrm{OH})_{3}$. Bayerite was converted to boehmite by hydrothermal treatment and then to $\gamma-\mathrm{Al}_{2} \mathrm{O}_{3}$ after calcination at $500^{\circ} \mathrm{C}$. The $\gamma-\mathrm{Al}_{2} \mathrm{O}_{3}$ recovered from the spent catalyst had a large surface area, and mono- and bi-modal pore size distribution with a very high total pore volume, as shown Figure 8.

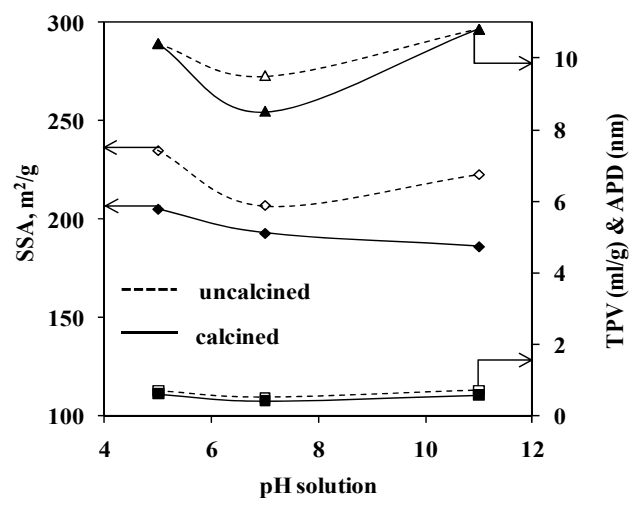

Figure 8: Role of $\mathrm{pH}$ on alumina textural properties.

\section{Conclusions}

This study concludes that soda roasting is economically beneficial by evaluating various environmental aspects; cost of safe disposal, high cost of recovered metals, and use of recovered alumina are the best solutions for handling hydroprocessing spent catalysts. The metal recovery results revealed that molybdenum and vanadium are selectively extracted over nickel and aluminum. Through $\mathrm{Na}_{2} \mathrm{CO}_{3}$ roasting, the residue can be further separated as nickel and bulk of solid alumina. The recovery of Mo and $\mathrm{V}$ strongly depend on the concentration of the roasting reagent $\mathrm{NaOH}$, but $\mathrm{Ni}$ did not react with in similar conditions. A complete Mo recovery was achieved from 87.7 to $99.9 \%$ when the ratio between the spent catalyst and $\mathrm{NaOH}$ in the mix was increased from $1: 0.4$ to $1: 1.5$. In the high pressure autoclave study, the rate of extraction of $\mathrm{V}$ and Mo was found reach its maximum at a temperature of $250^{\circ} \mathrm{C}$, and a further increase in temperature led no adverse effect on oxide extraction. A comparison between the two roasting agents has been concluded: the optimum conditions for maximum recovery of molybdenum and vanadium metals content were achieved at a reaction temperature of $700^{\circ} \mathrm{C}, 120$ min leaching time with $25 \%$ of $\mathrm{Na}_{2} \mathrm{CO}_{3}$ while using $\mathrm{NaOH}$, the optimum conditions were $480^{\circ} \mathrm{C}, 60$ min leaching time and $50 \%$ concentration.

\section{Acknowledgement}

The authors wish to thank the Kuwait Foundation for the Advancement of Science (KFAS) for their financial support (project: PF037C). 


\section{References}

[1] Marafi, M., Stanislaus, A. \& Furimsky, E., Handbook of Spent Hydroprocessing Catalysts: Regeneration, Rejuvenation, Reclamation, Environment and Safety, Elsevier; Oxford UK, 2010.

[2] Bartholomew, C.H., Agrawal, P.K. \& Katzer, J.R. Sulfur poisoning of metals. Adv. Catal., 31, 135-242, 1982.

[3] Marafi, M. \& Stanislaus, A., Spent catalyst waste management: A review: Part II-Advances in metal recovery and safe disposal method. Res., Cons. \& Recyc., 53, 1-26, $2008 \mathrm{a}$.

[4] Rana, M.S., Samano, V., Ancheyta, J. \& Diaz, J.A.I., A review of recent advances on process technologies for upgrading of heavy oils and residual. Fuel, 86, 1216-1231, 2007.

[5] Trimm, D.L., Deactivation and regeneration, in: Handbook of Heterogeneous Catalyst, eds. G. Ertl, H. Knozinger, J. Weitkamp, vol. 3 VCH Weinheim, 1997, 1263-1282.

[6] Rana, M. S., Ancheyta, J., Sahoo, S. K. \& Rayo, P., Carbon and metal deposition during the hydroprocessing of Maya crude oil. Catal. Today 220-222, 97-105, 2014.

[7] Furimsky, E. \& Massoth, F.E., Deactivation of hydroprocessing catalysts. Catal. Today, 52, 381-495, 1999.

[8] Mulak, W., Szymczycha, A., Lesniewicz, A. \& Zyrnicki, W., Preliminary results of metals leaching from a spent hydrodesulphurization (HDS) catalyst. Physicochemical Probl. of Mineral Processing, 40, 69-76, 2006.

[9] Marafi, M. \& Stanislaus, A., Options and processes for spent catalyst handling and utilization. J. Hazar. Mater., 101, 123-132, 2003.

[10] Marafi, M. \& Stanislaus, A., Studies on recycling and utilization of spent catalysts: Preparation of active HDM catalyst compositions from spent residue hydroprocessing catalysts. Appl. Catal. B: Env. 71, 199-206, 2007.

[11] Marafi, M. \& Stanislaus, A., Alumina from reprocessing of spent hydroprocessing catalyst. Catal. Today, 178, 117-123, 2011.

[12] Furimsky, E., Spent refinery catalysts: Environment safety and utilization. Catal. Today, 30, 223-286, 1996.

[13] Marafi, M. \& Stanislaus, A., Waste catalyst utilization: extraction of valuable metals from spent hydroprocessing catalysts by ultrasonicassisted leaching with acids. Ind. Eng. Chem. Res., 50, 9495-9501, 2011.

[14] Marafi, M. \& Stanislaus, A., Spent catalyst waste management: A review: Part I-Developments in hydroprocessing catalyst waste reduction and use. Res., Cons. \& Recyc., 52(6), 859-873, 2008 b.

[15] Marafi, M., Process for recovering boehmite and $\gamma-\mathrm{Al}_{2} \mathrm{O}_{3}$ from spent hydroprocessing catalyst, US Patent Application 2012/0051988A1.

[16] Al-Sheeha, H., Marafi, M., Raghavan, V. \& Rana, M. S. Recycling and recovery routes for spent hydroprocessing catalyst waste. Ind. Eng. Chem. Res., 52(36), 12794-12801, 2013. 
[17] Marafi, M. \& Stanislaus, A., Preparation of heavy oil hydrotreating catalyst from spent residue hydroprocessing catalysts. Catal. Today, 130, 421-428, 2008.

[18] Meena, M. Marafi, unpublished results 2014.

[19] Feng, Q., Shao, Y., Ou, L., Zhang, G. \& Lu, Y., Kinetics of nickel leaching from roasting-dissolving residue of spent catalyst with sulfuric acid. J. Central South University of Technology, 16(3), 410-415, 2009.

[20] Angelidis, T.N., Tourasanidis, E., Marinou, E. \& Stalidis, G.A., Selective dissolution of critical metals from diesel and naphtha spent hydrodesulphurization catalysts. Res., Cons. \& Recyc., 13, 269-282, 1995.

[21] Mohapatra, D. \& Park, K.H., Selective recovery of Mo, Co and Al from spent $\mathrm{CoMo} / \gamma-\mathrm{Al}_{2} \mathrm{O}_{3}$ catalyst: Effect of calcination temperature. J. Environ. Sci. Health. Part A Toxic/Hazard. Subst. Environ. Eng. 42, 507-515, 2007.

[22] Park, K.H., Mohapatra, D. \& Reddy, B.R., Selective recovery of molybdenum from spent HDS catalyst using oxidative soda ash leach/carbon adsorption method. J. Hazar. Mat. B, 138, 311-316, 2006 b. 